\title{
Chemoprevention in Prostate Cancer: Current Perspective and Future Directions
}

\author{
J. Ricardo Rivero, Jr., ${ }^{1}$ Ian M. Thompson, Jr., ${ }^{1,2}$ Michael A. Liss, ${ }^{1,2}$ and Dharam Kaushik ${ }^{1,2}$ \\ ${ }^{1}$ Department of Urology, University of Texas Health Science Center at San Antonio, San Antonio, Texas 78229 \\ ${ }^{2}$ Cancer Therapy and Research Center, University of Texas Health Science Center at San Antonio, San Antonio, \\ Texas 78229 \\ Correspondence: kaushik@uthscsa.edu
}

\begin{abstract}
Chemoprevention of prostate cancer aims to reduce the mortality as well as the public burden of overdetection, which increases anxiety, cost, and morbidity related to the disease. The role of 5 - $\alpha$-reductase inhibitors has been well investigated and shown to decrease the risk of prostate cancer. No current evidence exists to encourage the use of nutrients or vitamins as chemopreventive agents. The modulation of inflammation is one of the most promising targets for chemoprevention of prostate cancer.
\end{abstract}

$\mathrm{D}^{\prime}$ Michael B. Sporn defined cancer chemoprevention in the 1970s as "natural, synthetic or biological agents used to reverse, suppress or prevent either the initial phases of carcinogenesis or the progression of premalignant cells to invasive disease" (Sporn et al. 1976). The principle of effective chemoprevention entails targeting a population that will benefit most from the intervention, using agents and medications whose benefits outweigh its risks as well as being affordable (Sandhu et al. 2013). Since the identification of cancer risk factors, preventive strategies and research studies have flourished in an attempt to interrupt the carcinogenic pathway. By targeting specific carcinogenic pathways, chemoprevention intends to decrease the incidence of a disease as well as treatment-related complications and disease-specific mortality (Klein and Thompson 2012; Sandhu et al. 2013).

The long latency of carcinogenesis in prostate cancer makes it a suitable disease for che- moprevention (Parnes et al. 2005). It has been established that carcinogenesis in the prostate is likely caused by a high number of molecular alterations (Shtivelman et al. 2014). These molecular pathways result in precursor lesions like high-grade prostatic intraepithelial neoplasia (HGPIN). HGPIN is in itself a biologic entity. This precursor lesion can appear many years in advance before detecting cancer and provides a potential target population that benefits from chemoprevention. Ideally, chemoprevention of prostate cancer would impede the transformation of normal cells and precursor lesions to cancer, as well as stop and prevent the growth of existing tumors.

Prostate cancer has the prevalence of a disease well suited for chemoprevention as it presents a significant burden in the lives of many men. In the United States, an estimated 180,890 new cases of prostate cancer were diagnosed in 2015 , which resulted in 26,120 deaths related to

Editors: Michael M. Shen and Mark A. Rubin

Additional Perspectives on Prostate Cancer available at www.perspectivesinmedicine.org

Copyright (C) 2018 Cold Spring Harbor Laboratory Press; all rights reserved; doi: 10.1101/cshperspect.a030494

Cite this article as Cold Spring Harb Perspect Med 2018;8:a030494 
J.R. Rivero, Jr. et al.

prostate cancer (Siegel et al. 2016). This represents $21 \%$ of all incident cases and $8 \%$ of all deaths owing to malignancy in males (Siegel et al. 2016). The diagnosis of prostate cancer comes with a significant financial burden. Per the National Cancer Institute, the national cost of prostate cancer care in the United States in 2010 was estimated to be $\$ 11.85$ billion (Mariotto et al. 2011). Analysis of the cost effectiveness of chemoprevention has thus far proved that 5- $\alpha$-reductase inhibitors (5ARIs) are not cost effective in men with low risk of prostate cancer. However, they may be cost effective for men at increased risk for prostate cancer (Svatek et al. 2008; Earnshaw et al. 2013).

Given its potential and promising benefits, prostate cancer chemoprevention has become an area of active investigation. Three major trials have provided the highest level of evidence on prostate cancer chemoprevention. These trials are the Prostate Cancer Prevention Trial (PCPT) (Thompson et al. 2003a), Reduction by Dutasteride of Prostate Cancer Events (REDUCE) (Andriole et al. 2010), and Selenium and Vitamin E Cancer Prevention Trial (SELECT) (Lippman et al. 2009).

\section{5- $\alpha$-REDUCTASE INHIBITORS (5-ARIs)}

The role of androgens in the development and growth of benign prostate tissue as well as prostate cancer is well known and has been studied extensively. The hypothesis that 5ARIs may have beneficial effects in prostate cancer was solidified by the observation that males born with 5 $\alpha$-reductase deficiency do not suffer from prostate cancer. Further investigation helped us understand how the deregulation of androgen/ androgen-receptor (AR) pathways contribute to prostate cancer progression (Nacusi and Tindall 2011). Prostate tissue growth and differentiation is dependent on androgen hormones and regulated via the AR. Testosterone is irreversibly converted to more potent androgen 5 - $\alpha$-dihydrotestosterone (DHT) mediated by the androgen-metabolizing enzymes 5 - $\alpha$-reductase types 1 and 2 in the prostate tissue.

Type 2 is predominantly expressed in prostatic tissue (Thomas et al. 2005). Finasteride is an inhibitor of 5 - $\alpha$-reductase type 2 , inhibiting the conversion of testosterone to DHT mainly in the prostate. Dutasteride blocks the conversion to DHT of both types 1 and 2 of 5 - $\alpha$-reductase. Type 15 - $\alpha$-reductase became the focal point of research after studies revealed that, even though type 2 is the main form found in normal prostatic tissue, the overexpression of type 1 was seen in prostate cancer cell lines (Andriole et al. 2010).

\section{Finasteride}

In the PCPT, a randomized, placebo-controlled trial testing of whether finasteride could reduce the 7-year period prevalence of prostate cancer, finasteride reduced the risk of prostate cancer by $25 \%$. The PCPT became the first study, performed at a large scale, to explore the connection between finasteride and prostate cancer development (Thompson et al. 2003a). The PCPT was a prospective trial that followed 18,882 men, ages 55 and older, with a prostate-specific antigen (PSA) equal to or $<3.0 \mathrm{ng} / \mathrm{mL}$ and a normal digital rectal exam (DRE). The men were randomly assigned to take $5 \mathrm{mg}$ of finasteride daily or a placebo. Initially, the treatment was planned for 7 years and those subjects who were not diagnosed with prostate cancer in this time span were offered an end-of-study prostate biopsy. The data-monitoring committee overseeing the study closed the trial 15 months early as it deemed that the primary end point of prostate cancer reduction had been reached. The PCPT revealed that finasteride decreased the incidence of prostate cancer compared with placebo $18.4 \%$ versus $24.4 \%$, respectively. This meant that taking finasteride reduced prostate cancer prevalence by $24.8 \%$ over 7 years (Thompson et al. 2003a). In subsequent studies, it was found that treatment with finasteride positively affected the sensitivity of PSA and DRE for prostate cancer detection (Thompson et al. 2006, 2007).

An unforeseen discovery of the PCPT was a greater incidence of Gleason grade 7-10 cancer $(6.4 \%)$ in men taking finasteride as compared with the placebo arm (5.1\%) (Thompson et al. 2003a). Several reasons have been suggested to clarify the increase of high-grade tumors 
(Gleason 7-10) in the finasteride arm. Lucia et al. (2007) concluded that a reduction in prostate volume and selective inhibition of lowgrade prostate cancer might have contributed to an increase in diagnosis of high-grade prostate tumors. Similarly, Cohen et al. (2007) developed a model that showed how the diagnosis of high-grade prostate tumors decreased as prostatic volume increased, stressing that the median prostate volume was $25 \%$ lower in the finasteride arm of the PCPT. Additional studies have shown increased biopsy sensitivity in the finasteride arm of the PCPT (Redman et al. 2008). These findings, coupled with the fact that an increased incidence of Gleason 7-10 tumors appeared early in the PCPT and did not increase with time, diminish the theory that finasteride induces high-grade disease.

Eighteen years after the inception of the PCPT, long-term survival data among participants was analyzed. The 15-year survival rates were similar between groups; finasteride had a $78.0 \%$ survival rate compared with $78.2 \%$ for placebo. The 10-year survival rates were also similar after accounting for low-grade prostate cancer ( $83 \%$ finasteride vs. $80.9 \%$ placebo) and high-grade prostate cancer $(73.0 \%$ finasteride vs. 73.6\% placebo) (Thompson et al. 2013).

Finasteride was mostly well tolerated in the PCPT; nonetheless, it was associated with an increased occurrence of side effects such as reduced volume of ejaculate, erectile dysfunction, loss of libido, and gynecomastia (Thompson et al. 2003b). Although these side effects are inconvenient, the effect is small and they should not influence the patient's decision to take finasteride or the physician not to prescribe it (Moinpour et al. 2007).

\section{Dutasteride}

The chemopreventive role of dutasteride, a type I and II 5- $\alpha$-reductase inhibitor, was investigated in the REDUCE trial (Andriole et al. 2010). The study included men ages $50-75$ years old with a baseline PSA of $2.5-10.0 \mathrm{ng} / \mathrm{mL}$ who had a negative biopsy at least 6 months before the study. Contrary to the PCPT, protocol for the REDUCE trial required 10 core prostate biopsies to be performed at the 2- and 4-year marks, and other biopsies could also be performed if clinically indicated. Patients received either $0.5 \mathrm{mg}$ daily dose of dutasteride or placebo, with end points set at 2 and 4 years. The primary endpoint of the REDUCE trial was prostate cancer diagnosed on biopsy after 2 or 4 years of treatment. If a participant was found to have prostate cancer at the 2-year biopsy, he was withdrawn from the study. By the end of the study (4 years), prostate cancer detection was $19.9 \%$ in the dutasteride group compared with $25.1 \%$ in the placebo group. The difference between groups was truly significant and the chemopreventive effect of dutasteride was seen across all subgroups within the study that were stratified by age, family history, international prostate symptom score, prostate volume, PSA level, and body-mass index.

An increase in high-grade prostate cancer was not reported in the dutasteride arm of the REDUCE trial, unlike the finasteride group of the PCPT trial. Over the 4 years, Gleason 7-10 tumors were identified in $6.7 \%$ of men in the dutasteride arm versus $6.8 \%$ on the placebo arm. The overall decrease in cancer prevalence was seen in Gleason 6 or below tumors with a comparable prevalence of Gleason 7-10 tumors in the dutasteride and placebo groups. During the REDUCE trial 29, tumors with Gleason scores 8-10 were diagnosed in the dutasteride arm and 19 in the placebo arm. The numbers of tumors with Gleason scores 8-10 were similar in the dutasteride and placebo groups during years 1 and 2, 17, and 18, respectively. On years 3 and 4, 12 tumors with a Gleason score 8-10 were diagnosed in the dutasteride group versus only one in the placebo group. An explanation for the increase in high-grade Gleason 8-10 tumors in years 3 and 4 may lie within the REDUCE study design. Per protocol, subjects who had biopsies diagnosing tumors Gleason 5-7 in years 1 and 2 were withdrawn from the study, resulting in elimination of more men within the placebo arm. Andriole et al. (2010) speculated that if these men had not been withdrawn from the study, a portion of them may have been diagnosed with higher-grade tumors (Gleason 8-10) on biopsies in years 3 and 4 . This would reduce 
J.R. Rivero, Jr. et al.

the difference originally reported between the two groups.

Side effects reported with dutasteride during the REDUCE trial were decreased libido, loss of libido, erectile dysfunction, and gynecomastia. Unexpectedly, there was a statistically significant greater incidence of heart failure in the dutasteride arm versus the placebo arm ( $0.7 \%$ vs. $0.4 \%)$.

\section{DIETARY SUPPLEMENTS}

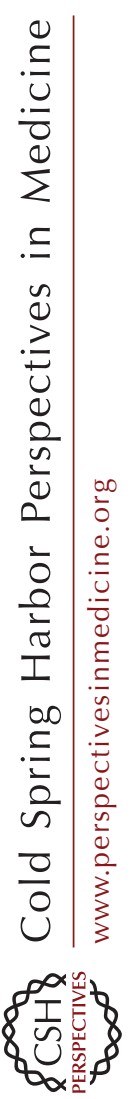

The interest of dietary and nutritional supplements as agents for chemoprevention of prostate cancer stems from several cohorts and randomized trials, most significantly the $\alpha$-Tocopherol $\beta$-Carotene Prevention Trial (ATBC) (ATBC 1994) and the Nutritional Prevention of Cancer (NPC) study (Clark et al. 1998). The ATBC trial was a lung cancer chemoprevention randomized study of more than 20,000 male smokers who received $50 \mathrm{mg}$ of $\alpha$-tocopherol or placebo. In 1998, the ATBC trial group reported a $32 \%$ reduction in the incidence of prostate cancer along with $41 \%$ less mortality in men taking $\alpha$-tocopherol supplements. These results were later disproved in a follow-up study in 2003 by the ATBC group finding that the beneficial effects of $\alpha$-tocopherol disappeared in postintervention follow-up (Virtamo et al. 2003). Selenium is a mineral that gained status as a chemopreventive agent for prostate cancer after the initial results of the NPC trial showed a risk reduction of $63 \%$ for prostate cancer in patients receiving selenium supplementation (Clark et al. 1998). These results were later disputed, and longer follow-up published in 2003 revealed the risk reduction to be smaller at $51 \%$ and only benefiting men with low baseline PSA and plasma selenium concentrations (Duffield-Lillico et al. 2003).

\section{Vitamin E and Selenium}

Both the ATBC and the NPC trials prompted the design of SELECT (Lippman et al. 2009; Klein et al. 2011), focusing specifically on the role of vitamin $\mathrm{E}$ and selenium in prostate cancer and not just as a secondary end point as in previous studies. The SELECT trial included 35,533 men without prostate cancer and a nor- mal DRE and a PSA of $4.0 \mathrm{ng} / \mathrm{mL}$ or less who were randomized to four groups: selenium (200 $\mu / d)$, vitamin E (400 IU/d), selenium + vitamin $\mathrm{E}$, and placebo. The SELECT trial, originally planned for a minimum of 7 years, was canceled after only a median follow-up of 5.46 years. The SELECT trial failed to show any benefit in reducing the incidence of prostate cancer in any of the groups compared with placebo (Lippman et al. 2009). Extended follow-up of the men enrolled in SELECT discovered that those taking vitamin $\mathrm{E}$ had a greater risk of developing prostate cancer $(17 \%)$ compared with placebo and that no beneficial effect was found with selenium intake (Klein et al. 2011). Further analysis of SELECT by Kristal et al. found that the effects of selenium and vitamin E supplementation varied considerably between men with low and high selenium status (measured by toenail selenium concentration) at baseline (Kristal et al. 2014). Results from this study indicated that selenium intake elevated the risk of high-grade prostate cancer by $91 \%$ in subjects that already had high baseline toenail selenium ( $\geq 60$ th percentile). The risk of prostate cancer was elevated by $63 \%$ in men taking vitamin $\mathrm{E}$ who also had low baseline toenail selenium (<40th percentile) (Kristal et al. 2014).

\section{Lycopene}

Lycopene is a carotenoid found in multiple fruits and vegetables such as tomatoes, watermelon, and asparagus, among others. This agent is most commonly consumed in tomato sauce and other tomato products (Thompson 2007). Studies investigating the beneficial effects of lycopene on prostate cancer risk reduction have been inconclusive. An analysis of 1338 prostate cancer cases in the Prostate, Lung, Colorectal, and Ovarian Cancer (PLCO) study of the National Cancer Institute, examined the consumption of lycopene and tomato products, concluding that increased lycopene and tomato product consumption did not protect from prostate cancer (Kirsh et al. 2006). On the other hand, a compelling argument for lycopene was made in a prospective study that included 49,898 patients (Zu et al. 2014). Starting in 1986 to January 2010 , dietary information was collected via 
questionnaires and paired with its corresponding confirmed total and lethal prostate cancer cases. Results showed that lycopene consumption was linked to a lower risk of lethal prostate cancer ( $\mathrm{Zu}$ et al. 2014). More studies and clinical trials that will clarify the chemopreventive benefits of lycopene are needed.

\section{Soy}

The effect of soy on prostate cancer has been the focus of research trials ever since epidemiologic studies showed a reduced incidence of prostate cancer in populations with higher intake of foods rich in isoflavones, a component of soy (Ahmad et al. 2013). A systematic review and meta-analysis of eight randomized control trials, which included men with identified risks for prostate cancer, supported a possible role of soy and isoflavones in prostate cancer risk reduction (van Die et al. 2014). Contrary to such promising results, a randomized control trial investigating the effect of soy supplementation on the biochemical recurrence of prostate cancer after radical prostatectomy failed to find a significant benefit to soy protein supplementation (Bosland et al. 2013). Additional well-designed studies are needed to reach a consensus on the role of soy for prostate cancer chemoprevention.

\section{OTHER MEDICATIONS}

\section{Toremifene}

Toremifene is a selective estrogen receptor modulator (SERM) that showed promise after it was found to decrease the incidence of prostate cancer through nonandrogren pathways in a mouse model of prostate cancer (Raghow et al. 2002). Toremifene was then studied in a phase IIb clinical trial for reducing prostate cancer risk in men with HGPIN (Price et al. 2006). In this clinical trial, 514 men with HGPIN were randomly assigned to take placebo, or 20, 40, $60 \mathrm{mg}$ of toremifene daily. Interestingly, results showed that only a dose of $20 \mathrm{mg}$ was linked to a reduced risk of prostate cancer at 12 months (48\%). This promising data gave way to a 3 -year phase III clinical trial that included 1590 men with
HGPIN who were randomized to placebo or $20 \mathrm{mg}$ of toremifene daily (Taneja et al. 2013). Unlike previous trials, this phase III clinical trial failed to show a statistically significant reduction in the incidence of prostate cancer as it was detected in $34.7 \%$ of men in the placebo group and $32.3 \%$ in the treatment group. Toremifene is not currently used as a chemopreventive agent for prostate cancer.

\section{Nonsteroidal Anti-Inflammatory Drugs}

Both nonsteroidal anti-inflammatory drugs (NSAIDs) and cyclooxygenase-2 (Cox-2) inhibitors have been studied for prostate cancer chemoprevention based on evidence suggesting that these drugs cause prostate cancer cell death (Dandekar et al. 2005). A significant reduction in prostate cancer risk was proposed in further analyses of clinical trials, cohorts, and case-control studies (Roberts et al. 2002; Dasgupta et al. 2006). Still other studies have not been as successful in proving the favorable effects of NSAIDs and Cox-2 inhibitors as chemopreventive agents for prostate cancer (Irani et al. 2002; Leitzmann et al. 2002). In addition to this, rofecoxib (selective Cox-2 inhibitor) was withdrawn from the market just as this medication was being investigated in a phase III clinical trial for prostate cancer chemoprevention (Thompson 2007). Given the premature closure of the phase III clinical trial and the mixed results reported in the various studies, the role of NSAIDs and Cox-2 inhibitors as agents for prostate cancer chemoprevention has been almost negligible.

\section{Statins}

Statins were found to suppress prostate cancer cells in vitro as well as reducing PSA in vivo (Chang et al. 2010; Wang et al. 2010). Evidence as to whether statins confer any benefit in reduction of prostate cancer risk has been conflicting. Secondary analysis of the REDUCE trial did not find a link between statin use and risk of overall or high-grade prostate cancer (Freedland et al. 2013). In contrast, a systematic review and metaanalysis of 13 studies found a reduced risk in prostate cancer-specific mortality (hazard ratio 
J.R. Rivero, Jr. et al.

[HR], 0.53; 95\% confidence interval [CI], 0.36$0.77 ; P, 0.01)$ in patients who were taking statins before the diagnosis of prostate cancer (Meng et al. 2016). Similarly, a risk reduction in prostate cancer-specific mortality was also noticed in patients who started taking statins after the diagnosis of prostate cancer ( $\mathrm{HR}, 0.64 ; 95 \% \mathrm{CI}$, $0.52-0.79 ; P, 0.01)$. Given the widespread use of statins, further studies are needed to clarify their clinical significance in prostate cancer prevention.

\section{INFLAMMATION AND PROSTATE CANCER CHEMOPREVENTION}

The influence of chronic infections and chronic inflammation in the development of epithelial malignancies has been well investigated. Chronic inflammation has been hypothesized to influence the development of prostate cancer (De Marzo et al. 2007). The carcinogenesis of prostate cancer may be linked to chronic inflammation the same way infections have been associated with liver and stomach malignancies. This hypothesis makes inflammation a target for chemoprevention.

A case-control study further investigated the link between inflammation and prostate cancer in a study derived from the PCPT. This study included 191 men diagnosed with prostate cancer (detected either on for-cause or end-of-study biopsy) and 209 men who were not diagnosed with prostate cancer on the end-of-study biopsy (control) (Gurel et al. 2014). The design of the PCPT inherently eliminated the bias of PSA, given that all subjects were offered an end-ofstudy biopsy, allowing researchers to investigate the relationship between inflammation and prostate cancer. In this case-control study, intraprostatic inflammation was commonly found in both benign prostate tissue (78.2\%) (controls) and prostate cancer-detected cases $(86.2 \%)$. The presence of inflammation was positively correlated with an increased risk of prostate cancer compared with subjects without inflammation on biopsy (OR, 1.78). This association was even greater in subjects with high-grade disease (Gleason 7-10) (OR, 2.24). Similar results were present after restricting to men with a low PSA
$(<2 \mathrm{ng} / \mathrm{mL})$, in whom inflammation had been less likely to influence biopsy recommendation (Gurel et al. 2014).

The results from the aforementioned study are different from a study derived from the Finnish Prostate Cancer Screening Trial (Yli-Hemminki et al. 2013), and another one derived from REDUCE (Moreira et al. 2014). Both of these studies concluded that if inflammation was present at the time of a negative biopsy, subjects had a decreased risk of prostate cancer. Unlike the PCPT, these studies only included subjects with history of a negative biopsy. These biopsies were likely prompted by an elevated PSA, and given that they were negative, the elevated PSA was perhaps a product of intraprostatic inflammation. Therefore, men with a previous negative biopsy showing inflammatory changes have a reduced probability of being diagnosed with prostate cancer in the future, compared with men with a previous negative biopsy without inflammation (Thompson et al. 2014).

\section{CONCLUSION}

Starting a 5-ARI as a chemopreventive agent is a decision that ultimately rests with the patient; however, the physician plays an important role. Along with discussing potential benefits and side effects of the medication, it is imperative that the patient be presented with all available information to make an educated decision. After counseling, it should be clear to the patient that 5-ARIs decrease the incidence of prostate cancer but will never completely eliminate it. Currently, no conclusive evidence exists to encourage the use of nutrients or vitamins as chemopreventive agents.

Over the past decades, many agents and strategies have been used with the intention to reduce cancer risk in the prostate. This is unique to prostate cancer unlike any other human malignancy. The future of prostate cancer chemoprevention seems to be focused on modulating inflammation and metabolic processes that can impact multiple disease processes. From a public health perspective, the idea of using one strategy that would reduce the prevalence of multiple diseases is exceedingly attractive. 


\section{REFERENCES}

Ahmad A, Biersack B, Li Y, Bao B, Kong D, Ali S, Banerjee S, Sarkar FH. 2013. Perspectives on the role of isoflavones in prostate cancer. AAPS J 15: 991-1000.

Andriole GL, Bostwick DG, Brawley OW, Gomella LG, Marberger M, Montorsi F, Pettaway CA, Tammela TL, Teloken C, Tindall DJ, et al. 2010. Effect of Dutasteride on the risk of prostate cancer. N Engl J Med 362: 1192-1202.

ATBC. 1994. The effect of vitamin $E$ and $\beta$ carotene on the incidence of lung cancer and other cancers in male smokers. The $\alpha$-Tocopherol, $\beta$-Carotene Cancer Prevention Study Group. N Engl J Med 330: 1029-1035.

Bosland MC, Kato I, Zeleniuch-Jacquotte A, Schmoll J, Enk Rueter E, Melamed J, Kong MX, Macias V, Kajdacsy-Balla A, Lumey LH, et al. 2013. Effect of soy protein isolate supplementation on biochemical recurrence of prostate cancer after radical prostatectomy: A randomized trial. JAMA 310: 170-178.

Chang SL, Harshman LC, Presti JC Jr. 2010. Impact of common medications on serum total prostate-specific antigen levels: Analysis of the National Health and Nutrition Examination Survey. J Clin Oncol 28: 3951-3957.

Clark LC, Dalkin B, Krongrad A, Combs GFJ, Turnbull BW, Slate EH, Witherington R, Herlong JH, Janosko E, Carpenter D, et al. 1998. Decreased incidence of prostate cancer with selenium supplementation: Results of a double-blind cancer prevention trial. Br J Urol 81: 730-734.

Cohen YC, Liu KS, Heyden NL, Carides AD, Anderson KM, Daifotis AG, Gann PH. 2007. Detection bias due to the effect of finasteride on prostate volume: A modeling approach for analysis of the Prostate Cancer Prevention Trial. J Natl Cancer Inst 99: 1366-1374.

Dandekar DS, Lopez M, Carey RI, Lokeshwar BL. 2005 Cyclooxygenase-2 inhibitor celecoxib augments chemotherapeutic drug-induced apoptosis by enhancing activation of caspase- 3 and -9 in prostate cancer cells. Int $J$ Cancer 115: 484-492.

Dasgupta K, Cesar DD, Ghosn J, Rajan R, Rahme E. 2006. Association between nonsteroidal anti-inflammatory drugs and prostate cancer occurrence. Cancer J 12: 130135.

De Marzo AM, Platz EA, Sutcliffe S, Xu J, Gronberg H, Drake CG, Nakai Y, Isaacs WB, Nelson WG. 2007. Inflammation in prostate carcinogenesis. Nat Rev Cancer 7: 256269.

Duffield-Lillico AJ, Dalkin BL, Reid ME, Turnbull BW, Slate EH, Jacobs ET, Marshall JR, Clark LC. 2003. Selenium supplementation, baseline plasma selenium status and incidence of prostate cancer: An analysis of the complete treatment period of the Nutritional Prevention of Cancer Trial. BJU Int 91: 608-612.

Earnshaw SR, Brogan AP, McDade CL. 2013. Model-based cost-effectiveness analyses for prostate cancer chemoprevention: A review and summary of challenges. Pharmacoeconomics 31: 289-304.

Freedland SJ, Hamilton RJ, Gerber L, Banez LL, Moreira DM, Andriole GL, Rittmaster RS. 2013. Statin use and risk of prostate cancer and high-grade prostate cancer: Results from the REDUCE study. Prostate Cancer Prostatic Dis 16: 254-259.
Gurel B, Lucia MS, Thompson IM Jr, Goodman PJ, Tangen CM, Kristal AR, Parnes HL, Hoque A, Lippman SM, Sutcliffe $\mathrm{S}$, et al. 2014. Chronic inflammation in benign prostate tissue is associated with high-grade prostate cancer in the placebo arm of the prostate cancer prevention trial. Cancer Epidemiol Biomarkers Prev 23: 847-856.

Irani J, Ravery V, Pariente JL, Chartier-Kastler E, Lechevallier E, Soulie M, Chautard D, Coloby P, Fontaine E, Bladou F, et al. 2002. Effect of nonsteroidal anti-inflammatory agents and finasteride on prostate cancer risk. J Urol 168: $1985-1988$.

Kirsh VA, Mayne ST, Peters U, Chatterjee N, Leitzmann MF, Dixon LB, Urban DA, Crawford ED, Hayes RB. 2006. A prospective study of lycopene and tomato product intake and risk of prostate cancer. Cancer Epidemiol Biomarkers Prev 15: 92-98.

Klein EA, Thompson IM. 2012. Chemoprevention of prostate cancer: An updated view. World J Urol 30: 189-194.

Klein EA, Thompson IM Jr, Tangen CM, Crowley JJ, Lucia MS, Goodman PJ, Minasian LM, Ford LG, Parnes HL, Gaziano JM, et al. 2011. Vitamin E and the risk of prostate cancer: The Selenium and Vitamin E Cancer Prevention Trial (SELECT). JAMA 306: 1549-1556.

Kristal AR, Darke AK, Morris JS, Tangen CM, Goodman PJ, Thompson IM, Meyskens FL Jr, Goodman GE, Minasian LM, Parnes HL, et al. 2014. Baseline selenium status and effects of selenium and vitamin E supplementation on prostate cancer risk. J Natl Cancer Inst 106: djt456.

Leitzmann MF, Stampfer MJ, Ma J, Chan JM, Colditz GA, Willet WC, Giovannucci E. 2002. Aspirin use in relation to risk of prostate cancer. Cancer Epidemiol Biomarkers Prev 11: 1108-1111.

Lippman SM, Klein EA, Goodman PJ, Lucia MS, Thompson IM, Ford LG, Parnes HL, Minasian LM, Gaziano JM, Hartline JA, et al. 2009. Effect of selenium and vitamin E on risk of prostate cancer and other cancers. JAMA 301: 39-51.

Lucia MS, Epstein JI, Goodman PJ, Darke AK, Reuter VE, Civantos F, Tangen CM, Parnes HL, Lippman SM, La Rosa FG, et al. 2007. Finasteride and high-grade prostate cancer in the Prostate Cancer Prevention Trial. J Natl Cancer Inst 99: 1375-1383.

Mariotto AB, Yabroff KR, Shao Y, Feuer EJ, Brown ML. 2011. Projections of the cost of cancer care in the United States: 2010-2020. J Natl Cancer Inst 103: 117-128.

Meng Y, Liao YB, Xu P, Wei WR, Wang J. 2016. Statin use and mortality of patients with prostate cancer: A metaanalysis. Onco Targets Ther 9: 1689-1696.

Moinpour CM, Darke AK, Donaldson GW, Thompson IM Jr, Langley C, Ankerst DP, Patrick DL, Ware JE Jr, Ganz PA, Shumaker SA, et al. 2007. Longitudinal analysis of sexual function reported by men in the Prostate Cancer Prevention Trial. J Natl Cancer Inst 99: 1025-1035.

Moreira DM, Nickel JC, Gerber L, Muller RL, Andriole GL, Castro-Santamaria R, Freedland SJ. 2014. Baseline prostate inflammation is associated with a reduced risk of prostate cancer in men undergoing repeat prostate biopsy: Results from the REDUCE study. Cancer 120: 190-196.

Nacusi LP, Tindall DJ. 2011. Targeting $5 \alpha$-reductase for prostate cancer prevention and treatment. Nat Rev Urol 8: $378-384$. 
J.R. Rivero, Jr. et al.

Parnes HL, Thompson IM, Ford LG. 2005. Prevention of hormone-related cancers: Prostate cancer. J Clin Oncol 23: $368-377$

Price D, Stein B, Sieber P, Tutrone R, Bailen J, Goluboff E, Burzon D, Bostwick D, Steiner M. 2006. Toremifene for the prevention of prostate cancer in men with high grade prostatic intraepithelial neoplasia: Results of a doubleblind, placebo controlled, phase IIB clinical trial. J Urol 176: 965-970; discussion 970-961.

Raghow S, Hooshdaran MZ, Katiyar S, Steiner MS. 2002. Toremifene prevents prostate cancer in the transgenic adenocarcinoma of mouse prostate model. Cancer Res 62: $1370-1376$.

Redman MW, Tangen CM, Goodman PJ, Lucia MS, Coltman CA Jr, Thompson IM. 2008. Finasteride does not increase the risk of high-grade prostate cancer: A biasadjusted modeling approach. Cancer Prev Res (Phila) 1: 174-181.

Roberts RO, Jacobson DJ, Girman CJ, Rhodes T, Lieber MM, Jacobsen SJ. 2002. A population-based study of daily nonsteroidal anti-inflammatory drug use and prostate cancer. Mayo Clin Proc 77: 219-225.

Sandhu GS, Nepple KG, Tanagho YS, Andriole GL. 2013. Prostate cancer chemoprevention. Semin Oncol 40: 276285.

Shtivelman E, Beer TM, Evans CP. 2014. Molecular pathways and targets in prostate cancer. Oncotarget 5: 72177259 .

Siegel RL, Miller KD, Jemal A. 2016. Cancer statistics, 2016. CA Cancer J Clin 66: 7-30.

Sporn MB, Dunlop NM, Newton DL, Smith JM. 1976. Prevention of chemical carcinogenesis by vitamin $A$ and its synthetic analogs (retinoids). Fed Proc 35: 1332-1338.

Svatek RS, Lee JJ, Roehrborn CG, Lippman SM, Lotan Y. 2008. Cost-effectiveness of prostate cancer chemoprevention: A quality of life-years analysis. Cancer 112: 1058 1065.

Taneja SS, Morton R, Barnette G, Sieber P, Hancock ML, Steiner M. 2013. Prostate cancer diagnosis among men with isolated high-grade intraepithelial neoplasia enrolled onto a 3-year prospective phase III clinical trial of oral toremifene. J Clin Oncol 31: 523-529.

Thomas LN, Lazier CB, Gupta R, Norman RW, Troyer DA, O'Brien SP, Rittmaster RS. 2005. Differential alterations in 5o-reductase type 1 and type 2 levels during development and progression of prostate cancer. Prostate 63: 231-239.

Thompson IM. 2007. Chemoprevention of prostate cancer Agents and study designs. J Urol 178: S9-S13.
Thompson IM, Goodman PJ, Tangen CM, Lucia MS, Miller GJ, Ford LG, Lieber MM, Cespedes RD, Atkins JN, Lippman SM, et al. 2003a. The influence of finasteride on the development of prostate cancer. N Engl J Med 349: 215224.

Thompson IM, Tangen C, Goodman P. 2003b. The Prostate Cancer Prevention Trial: Design, status, and promise. World J Urol 21: 28-30.

Thompson IM, Chi C, Ankerst DP, Goodman PJ, Tangen CM, Lippman SM, Lucia MS, Parnes HL, Coltman CA Jr. 2006. Effect of finasteride on the sensitivity of PSA for detecting prostate cancer. J Natl Cancer Inst 98: 11281133 .

Thompson IM, Pauler Ankerst D, Chi C, Goodman PJ, Tangen CM, Lippman SM, Lucia MS, Parnes HL, Coltman CA Jr. 2007. Prediction of prostate cancer for patients receiving finasteride: Results from the Prostate Cancer Prevention Trial. J Clin Oncol 25: 3076-3081.

Thompson IM Jr, Goodman PJ, Tangen CM, Parnes HL, Minasian LM, Godley PA, Lucia MS, Ford LG. 2013. Long-term survival of participants in the prostate cancer prevention trial. N Engl J Med 369: 603-610.

Thompson IM, Kristal AR, Platz A. 2014. Prevention of prostate cancer: Outcomes of clinical trials and future opportunities. Am Soc Clin Oncol Educ Book 2014: e76-e80.

van Die MD, Bone KM, Williams SG, Pirotta MV. 2014. Soy and soy isoflavones in prostate cancer: A systematic review and meta-analysis of randomized controlled trials. BJU Int 113: E119-E130.

Virtamo J, Pietinen P, Huttunen JK, Korhonen P, Malila N, VM J, Albanes D, Taylor PR, Albert P. 2003. Incidence of cancer and mortality following $\alpha$-tocopherol and $\beta$ carotene supplementation: A post intervention follow up. JAMA 290: 476-485.

Wang C, Tao W, Wang Y, Bikow J, Lu B, Keating A, Verma S, Parker TG, Han R, Wen XY. 2010. Rosuvastatin, identified from a zebrafish chemical genetic screen for antiangiogenic compounds, suppresses the growth of prostate cancer. Eur Urol 58: 418-426.

Yli-Hemminki TH, Laurila M, Auvinen A, Maattanen L, Huhtala H, Tammela TL, Kujala PM. 2013. Histological inflammation and risk of subsequent prostate cancer among men with initially elevated serum prostate-specific antigen (PSA) concentration in the Finnish prostate cancer screening trial. BJU Int 112: 735-741.

Zu K, Mucci L, Rosner BA, Clinton SK, Loda M, Stampfer MJ, Giovannucci E. 2014. Dietary lycopene, angiogenesis, and prostate cancer: A prospective study in the prostatespecific antigen era. J Natl Cancer Inst 106: djt430. 


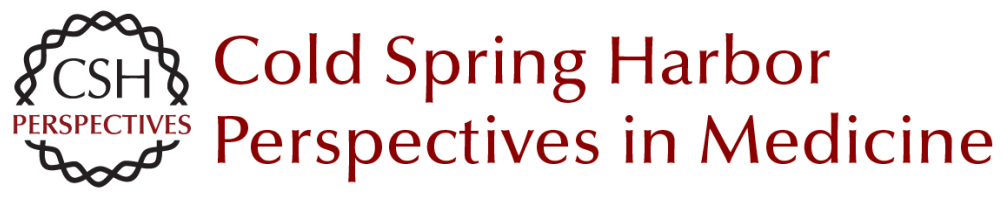

\section{Chemoprevention in Prostate Cancer: Current Perspective and Future Directions}

J. Ricardo Rivero, Jr., Ian M. Thompson, Jr., Michael A. Liss and Dharam Kaushik

Cold Spring Harb Perspect Med 2018; doi: 10.1101/cshperspect.a030494 originally published online January 8, 2018

\section{Subject Collection Prostate Cancer}

Anatomic and Molecular Imaging in Prostate

Cancer

Eric T. Miller, Amirali Salmasi and Robert E. Reiter

The Epidemiology of Prostate Cancer

Claire H. Pernar, Ericka M. Ebot, Kathryn M. Wilson, et al.

Prostate Stem Cells and Cancer Stem Cells Jia J. Li and Michael M. Shen

Prostate Cancer Epigenetics: From Basic Mechanisms to Clinical Implications Srinivasan Yegnasubramanian, Angelo M. De Marzo and William G. Nelson

The Genomics of Prostate Cancer: A Historic Perspective Mark A. Rubin and Francesca Demichelis

Neuroendocrine Differentiation in Prostate Cancer: Emerging Biology, Models, and Therapies Loredana Puca, Panagiotis J. Vlachostergios and Himisha Beltran

DNA Damage Response in Prostate Cancer Matthew J. Schiewer and Karen E. Knudsen

Transcriptional Regulation in Prostate Cancer David P. Labbé and Myles Brown
New Opportunities for Targeting the Androgen

Receptor in Prostate Cancer Margaret M. Centenera, Luke A. Selth, Esmaeil Ebrahimie, et al.

Prostate Cancer Research at the Crossroads Michael M. Shen and Mark A. Rubin

Immunotherapy for Prostate Cancer Nicholas J. Venturini and Charles G. Drake

Molecular Pathology of High-Grade Prostatic Intraepithelial Neoplasia: Challenges and Opportunities Levent Trabzonlu, Ibrahim Kulac, Qizhi Zheng, et al.

Metastases in Prostate Cancer Federico La Manna, Sofia Karkampouna, Eugenio Zoni, et al.

Genetically Engineered Mouse Models of Prostate Cancer in the Postgenomic Era Juan M. Arriaga and Cory Abate-Shen

Molecular Biomarkers in the Clinical Management of Prostate Cancer Aaron M. Udager and Scott A. Tomlins

Metabolic Vulnerabilities of Prostate Cancer: Diagnostic and Therapeutic Opportunities Giorgia Zadra and Massimo Loda

For additional articles in this collection, see http://perspectivesinmedicine.cshlp.org/cgi/collection/ 